\title{
Pengaruh Fasilitas Dan Lingkungan Belajar Terhadap Motivasi Belajar
}

\author{
Bahrudi Efendi Damanik \\ Manajemen Informaatika, AMIK-STIKOM Tunas Bangsa Pematangsiantar \\ bahrudiefendi@gmail.com
}

\begin{abstract}
ABSTRAK
Tujuan penelitian ini adalah untuk mengetahui pengaruh fasilitas belajar terhadap motivasi belajar, pengaruh lingkungan belajar terhadap motivasi belajar, dan pengaruh fasilitas belajar dan lingkungan belajar terhadap motivasi belajar. Populasi dan sampel dalam penelitian ini berjumlah 81 orang. Metode yang digunakan adalah metode sampling jenuh yaitu teknik pengumpulan data melalui wawancara, survei dan penyebaran kuesioner kepada responden. Data yang telah didistribusikan kemudian diproses menggunakan skala Likert. Teknik analisis data yang digunakan dalam penelitian ini adalah analisis regresi linier berganda, uji asumsi klasik, uji t, uji F dan koefisien determinan. Hasil analisis menunjukkan bahwa fasilitas pembelajaran parsial berpengaruh positif dan signifikan terhadap motivasi belajar, $t$ hitung $>$ ttabel $(2,390>1,991)$, lingkungan belajar parsial berpengaruh positif dan signifikan terhadap motivasi belajar, $t$ hitung $>$ ttabel $(4,229>1,991)$, dan hasil penelitian dan lingkungan belajar secara bersamaan memiliki pengaruh positif dan signifikan terhadap motivasi belajar, Fhitung $>$ Ftabel $(25,872>2,720)$.
\end{abstract}

Kata kunci: Fasilitas, lingkungan belajar, motivasi belajar

\section{PENDAHULUAN}

Pendidikan diharapkan dapat menghasilkan manusia yang berkualitas dan bertanggung jawab serta mampu menyongsong kemajuan pada masa mendatang.Pendidikan juga berfungsi mengembangkan kemampuan dan membentuk watak serta peradaban bangsa yang bermartabat karena kemajuan suatu bangsa juga dapat dilihat dari seberapa maju pendidikan yang dimiliki.

Dalam UU No. 20 tahun 2003 pasal 3 tentang sistem pendidikan nasional bahwa pendidikan nasional berfungsi mengembangkan kemampuan dan membentuk watak serta peradaban bangsa yang bermartabat dalam rangka mencerdaskan kehidupan bangsa, bertujuan untuk mengembangkan potensi peserta didik agar menjadi manusia yang beriman dan bertaqwa kepada Tuhan Yang Maha Esa, berakhlak mulia, sehat, berilmu, cakap, kreatif, mandiri dan menjadi warga negara yang demokratis serta bertanggung jawab.

Motivasi dapat diartikan sebagai daya penggerak yang telah menjadi aktif. Motif menjadi aktif pada saat tertentu, terutama bila kebutuhan untuk mencapai tujuan sangat dirasakan atau mendesak. Motivasi yang kuat akan menumbuhkan gairah, semangat, dan perasaan senang untuk belajar. Seseorang akan menampakkan minat, perhatian, konsentrasi penuh, ketekunan tinggi, serta berorientasi pada prestasi tanpa mengenal perasaan bosan apabila ia mempunyai motivasi belajar. Hakim (2000:26) mengatakan motivasi sebagai suatu dorongan kehendak yang menyebabkan seseorang melakukan suatu perbuatan untuk mencapai tujuan.

Hal ini sejalan dengan penelitian yang dilakukan oleh Lukman Sunadi (2013:3) yaitu salah satu faktor internal yang mempengaruhi prestasi belajar siswa adalah motivasi belajar. Motivasi merupakan faktor penting dalam meningkatkan prestasi belajar. Adanya motivasi yang tinggi dalam belajar akan mengakibatkan hasil belajar yang baik.

Dalam pengamatan penulis melalui Kartu Hasil Studi (KHS) yang dikeluarkan oleh bagian pendidikan program studi Komputerisasi Akuntansi, dampak dari kurangnya motivasi mahasiswa dalam mengikuti mata kuliah Aplikasi Akuntansi setelah masa perkuliahan semester III selesai masih belum memuaskan, kisaran nilai yang diperoleh mahasiswa masih di angka 65 75, atau kalau di konversi dengan nilai huruf berarti masih pada grade nilai C dan B.

Hal lainya juga dalam pengamatan penulis, mahasiswa yang mengikuti mata kuliah aplikasi akuntansi belum mampu mengerjakan satu kasus soal yang berisi satu siklus akuntansi dalam satu periode akuntansi tertentu. Masalah ini menjadi penting untuk diperhatikan bagi keberhasilan proses belajar mengajar agar nantinya dikemudian hari ketika mahasiswa telah selesai 
kuliah dapat segera mengaplikasikan ilmunya kedunia kerja, atau dunia wira usaha, juga memperoleh nilai yang baik khususnya dalam mata kuliah Aplikasi Akuntansi.

Untuk mencari solusi atas permasalahan tersebut penulis menganggap perlu diadakan penelitian lebih jauh agar dapat mengetahui sumber permasalahannya. Faktor-faktor yang menjadi perhatian penulis berkaitan dengan kurangnya motivasi mahasiswa dalam mencapai tujuan belajar aplikasi akuntansi antara lain fasilitas belajar, dan lingkungan belajar.

Faktor yang perlu diperhatikan untuk menumbuhkan motivasi belajar adalah fasilitas belajar. Arikunto (2002:6) berpendapat "Fasilitas belajar adalah segala sesuatu yang dapat memudahkan dan melancarkanpelaksanaan suatu usaha“. Seorang mahasiswa seharusnya lebih giat untuk belajar ketika fasilitas belajar memadai. Wuryani (2002:329) menyatakan bahwa "Fasilitas belajar yang lengkap, guru disediakan, dan gedungdibuatdengan harapan supaya mahasiswa bersemangat. Tetapi semua akan sia-sia jikatidak ada motivasi untuk belajar".

Semakin baik dan lengkap fasilitas yang diberikan, maka akan menambah motivasi mahasiswa dalam melaksanakan kegiatan belajar mengajar, sebaliknya bila fasilitas hanya apa adanya, hanya sebatas memenuhi syarat asal ada, tentunya akan mempengaruhi motivasi belajar mahasiswa. Amik Tunas Bangsa sebaiknya memberi perhatian lebih akan kelengkapan fasilitas belajarnya, seperti, sarana laboratorium komputer yang memadai dengan softwaresoftware khususnya, software akuntansi yang selalu up to date, fasilitas internet yang tanpa batas, in focus yang tersedia permanen di tiap kelas lab, kelas lab yang berpendingin ruangan yang memadai, dan fasilitas lainnya yang akan menunjang meningkatnya motivasi belajar mahasiswa.

Suasana lingkungan belajar yang tercipta tergantung dari bagaimana mahasiswa itu bisa mengatasi dan mengendalikan dirinya sendiri saat berada dalam lingkungan belajarnya. Lingkungan belajar oleh para ahli sering disebut sebagai lingkungan pendidikan. Suasana kelas yang positif akan terjadi bila interaksi dalam kelas terjadi antara dosen dan mahasiswa, dimana dalam interaksi tersebut terjadi komunikasi dalam bentuk belajar bersama, tolong menolong, tenggang rasa antara mahasiswa yang pandai dan kurang pandai, antara yang kaya dan yang kurang mampu, norma-norma pergaulan hidup dan tata tertib kelas maupun kampus dipatuhi dengan fasilitas yang luwes, serta terjadi komunikasi yang terbuka (Dariyo, 2008: 44).

Lingkungan belajar sangat berperan dalam menciptakan gairahmahasiswa dan secara sosial sangat berpengaruh terhadap proses pembelajaran Lingkungan belajar dapat meningkatkan keaktifan mahasiswa dan keefektifan belajar. Lingkungan belajar tidak hanya secara langsung mempengaruhi tinggi rendahnya hasil belajar, lingkungan belajar juga akan menyentuh ranah kognitif atau personal siswa(Sumiati, 2012: 4). Dalam proses belajar mengajar, lingkungan merupakan sumber belajar yang berpengaruh dalam keberhasilan proses belajar dan peningkatan perkembangan anak. Tempat dimana kegiatan belajar berlangsung yang mendapatkan pengaruh dari luar terhadap keberlangsungan kegiatan tersebut. Lingkungan yang merupakan sumber belajar memiliki pengaruh dalam proses pembelajaran.

Berdasarkan latar belakang masalah diatas, maka rumusan masalah dalampenelitian ini adalah :1) Bagaimana pengaruh fasilitas belajar terhadap motivasi belajar di AMIK Tunas Bangsa Pematangsiantar? 2) Bagaimana pengaruh lingkungan belajar terhadap motivasi belajar di AMIK Tunas Bangsa Pematangsiantar? Dan 3) Bagaimana pengaruh pengaruh fasilitas belajar, dan lingkungan belajar terhadap motivasi belajar di AMIK Tunas Bangsa Pematangsiantar?

\section{METODE PENELITIAN}

\section{Lokasi dan Objek Penelitian}

Penelitian ini dilakukan di Amik Tunas Bangsa Pematangsiantar, Jalan udirman No. 123 Pematangsiantar, dengan objek penelitian adalah adalah mahasiswa angkatan 2015/2016 Prodi Komputersasi Akuntansi yang berjumlah 81 mahasiswa. Jumlah populasi adalah jumlah mahasiswa yang mengikuti mata kuliah aplikasi akuntansi.

\section{Teknik Pengumpulan Data}

Untuk mengumpulkan data dan memperoleh data yang akurat, penulis menggunakan teknik pengumpulan data yang lazim digunakan yang bersumber dari dalam maupun dari luar sekolah. Teknik yang digunakan untuk pengumpulan data ini adalah sebagai berikut:

1. Penelitian Kepustakaan (Library Research) Suatu cara yang dilakukan dengan mengumpulkan data-data yang diperoleh melalui lietratur dengan buku-buku bacaan, serta tulisan-tulisan ilmiah yang berkaitan 
dengan permasalahan yang dibahas. Data yang diperoleh adalah data sekunder yang bersifat teoritis.

2. Penelitian Lapangan (Field Research)

Dalam Umar (2002: 91-94) ada beberapa teknik pengumpulan data primer, yaitu wawancara, angket dan observasi. Pengumpulan data primer tersebut menggunakan perangkat atau instrument sendiri-sendiri.

a. Wawancara (interview) yaitu penulis mengadakan wawancara langsung ke bagian-bagian yang terkait dalam penelitian untuk penulisan ini.

b. Angket (quesioner) yaitu sejumlah pertanyaan yang berkaitan dengan permasalahan yang disebarkan kepada responden untuk kemudian disajikan dalam bentuk tabulasi.

c. Pengamatan (observasi) yaitu data-data yang diperoleh dari hasil penelitian langsung terhadap pelaksanaan kegiatan.

\section{Pengujian Hipotesis}

Dalam penelitian ini untuk menguji hipotesis penelitian menggunakan analisis regresi linier berganda yaitu melihat pengaruh variabel independent (variabel bebas) terhadap variabel dependent (variabel terikat), dengan menggunakan persamaan matematis yaitu analisis regresi linier berganda dengan rumus :

$$
\mathbf{Y}=\mathbf{a}+\mathbf{b} 1 \mathbf{X} 1+\mathbf{b} 2 \mathbf{X} 2+\mathbf{E}
$$

\section{Dimana :}

Y $\quad=$ Motivasi belajar

A $\quad=$ Konstanta

b1 $=$ Koefesien regresi variabel $\mathrm{x}_{1}$

$\mathrm{b}_{2} \quad=$ Koefesien regresi variabel $\mathrm{x}_{2}$

$\mathrm{X}_{1} \quad=$ Fasilitas

$\mathrm{X}_{2} \quad=$ Lingkungan belajar

Analisis regresi linier berganda meliputi uji Koefisien Determinasi $\left(\mathrm{R}^{2}\right)$ bertujuan untuk melihat sumbangan efektif variabel $\mathrm{X} 1 ; \mathrm{X} 2$; dalam menjelaskan variabel $\mathrm{Y}$, uji $\mathrm{F}$ bertujuan melihat pengaruh secara simultan variabel $\mathrm{X}$; $\mathrm{X} 2$ terhadap variabel $\mathrm{Y}$ dan uji $\mathrm{t}$ untuk melihat pengaruh secara parsial masing-masing variabel $\mathrm{X} 1$; X2 terhadap variabel $\mathrm{Y}$, dan lebih lengkapnya dapat dilihat penjelasan berikut ini:

\section{Uji t (Pengujian Secara Parsial)}

Uji t dilakukan untuk mengetahui pengaruh masing-masing variabel independen secara parsial terhadap variabel dependen. Uji $t$ dilakukan dengan embandingkan $t$ hitung terhadap $\mathrm{t}$ tabel dengan ketentuan sebagai berikut : $\mathrm{H} 0: \beta=0$, berarti tidak ada pengaruh signifikan dari masing-masing variabel independent terhadap variabel dependent.

Ha : $\beta>0$, berarti ada pengaruh yang signifikan dari masing-masing variabel independent terhadap variabel dependent secara partial.

Tingkat kepercayaan yang digunakan adalah $95 \%$ atau taraf signifikan $5 \%(\lambda=0,05)$ dengan kriteria sebagai berikut :

a. Jika $t$ hitung $>t$ tabel dan probabilitas (nilai signifikan $)<$ tingkat signifikansi $5 \%((\lambda=$ $0,05)$ maka Ha diterima dan $\mathrm{H} 0$ ditolak berarti ada pengaruh yang signifikan dari masing-masing variabel independent terhadap variabel dependent.

b. Jika $t$ hitung $<\mathrm{t}$ tabel dan probabilitas (nilai signifikansi) $>$ tingkat signifikansi $5 \%((\lambda=$ $0,05)$ maka H0 diterima dan Ha ditolak berarti tidak ada pengaruh yang signifikan dari masing-masing variabel independent terhadap variabel dependent. Dimana $t$ tabel ditentukan dengan mencari derajat bebasnya yaitu $\mathrm{df}=\mathrm{N}-\mathrm{k}-1$

\section{Uji F (Pengujian Simultan)}

Pengujian ini dilakukan untuk mengetahui apakah semua variabel independen secara bersama-sama (simultan) dapat berpengaruh terhadap variabel dependent. Cara yang digunakan adalah dengan membandingkan nilai $\mathrm{F}$ hitung dengan $\mathrm{F}$ tabel dengan ketentuan sebagai berikut :

$\mathrm{H} 0: \beta=0$, berarti tidak ada pengaruh signifikan dari variabel independen terhadap variabel dependen secara simultan.

Ha : $\beta>0$, berarti ada pengaruh yang signifikan dari variabel independen terhadap variabel dependen secara simultan.

Tingkat kepercayaan yang digunakan adalah 95\% atau taraf signifikan $5 \%(\lambda=0,05)$ dengan kriteria sebagai berikut :

a. Jika $\mathrm{F}$ hitung $>\mathrm{F}$ tabel dan probabilitas (nilai signifikan $)<$ tingkat signifikansi $5 \%((\lambda=$ $0,05)$ maka Ha diterima dan $\mathrm{H} 0$ ditolak berarti ada variabel independent secara bersama-sama mempunyai pengaruh yang signifikan terhadap variabel dependent.

b. Jika F hitung $<\mathrm{F}$ tabel dan probabilitas (nilai signifikansi $)>$ tingkat signifikansi $5 \%((\lambda=$ $0,05)$ maka $\mathrm{H} 0$ diterima dan Ha ditolak berarti ada variabel independent secara bersama-sama tidak mempunyai pengaruh 
yang signifikan terhadap variabel dependent. Dimana $\mathrm{F}$ tabel ditentukan dengan mencari derajat bebasnya yaitu $\mathrm{df} 1=\mathrm{k}-1$ dan $\mathrm{df} 2=\mathrm{N}-\mathrm{k}$, dimana $\mathrm{N}=$ jumlah sampel dan $\mathrm{k}=$ jumlah variabel.

\section{Koefisien Determinasi $\left(\mathbf{R}^{2}\right)$}

Koefisien determinasi $\left(\mathrm{R}^{2}\right)$ pada intinya mengukur seberapa besar kemampuan variabel independent yaitu (X1) dan (X2) dalam menerangkan variasi variabel dependent $(\mathrm{Y})$. Nilai koefisien determinasi adalah antara nol (0) sampai dengan satu (1). Nilai $\mathrm{R}^{2}$ yang kecil berarti kemampuan variabel-variabel independent dalam menjelaskan variasi variabel dependent amat terbatas. Nilai yang mendekati satu berarti variabel-variabel independent memberikan hampir semua informasi yang dibutuhkan untuk memprediksi variasi dependent. Secara umum koefisien determinasi untuk data silang (crosssection) relatif rendah karena adanya variasi yang besar antara masing-masing pengamatan, sedangkan untuk data runtun waktu (time series) biasanya mempunyai nilai koefisien determinasi yang tinggi. Kelemahan mendasar penggunaan koefisien determinasi adalah bias terhadap jumlah variabel independent yang dimasukkan kedalam model. Setiap tambahan satu variabel independent, maka $\mathrm{R}^{2}$ pasti meningkat tidak peduli apakah variabel tersebut berpengaruh secara signifikan terhadap variabel dependent. Oleh karena itu banyak peneliti menganjurkan untuk menggunakan nilai Adjusted $R^{2}$ (Adjusted $R$ Square) pada saat mengevaluasi dimana model regresi terbaik. Tidak seperti $\mathrm{R}^{2}$, nilai Adjusted $\mathrm{R}^{2}$ dapat naik atau turun apabila satu variabel independent ditambahkan ke dalam model. Untuk variabel independent lebih dari dua sebaiknya menggunakan nilai Adjusted $\mathrm{R}^{2}$.

\section{HASIL \& PEMBAHASAN}

Kegiatan pengabdian "PKM Uji Normalitas

Uji Normalitas digunakan untuk mengetahui apakah data-data berasal dari populasi yang memiliki sebaran atau distribusi normal. Uji normalitas data dalam penelitian ini menggunakan metode Lilliefors melalui uji Kolmogrov-Smirnov dalam program SPSS 22. Untuk menolak atau menerima hipotesis dengan cara membandingkan nilai probabilitas dengan taraf signifikansi $(\alpha)=5 \%$. Jika nilai probabilitas lebih besar dari 0.05 maka dapat dinyatakan bahwa data berdistribusi normal.

Tabel 1. Uji Normalitas

\begin{tabular}{llll} 
Variable & Nilai Probabilitas & Nilai Signifikan & Keputusan \\
\hline Fasilitas & .200 & 0.05 & Normal \\
\hline Lingkungan Belajar & .200 & 0.05 & Normal \\
\hline Motivasi Belajar & .012 & 0.05 & Normal \\
\hline
\end{tabular}

Dari hasil perhitungan uji normalitas, seluruh nilai probabilitas lebih besar dari 0.05 , Nilai Sign, untuk Fasiltas $0,200>0,05$,Nilai Sign. untuk Lingkungan Belajar adalah 0,200 >0,05 dan Nilai Sign. Motivasi Belajar 0,12>0,05, sehingga data tersebut dinyatakan berdistribusi normal atau mempunyai sebaran data normal.

Sedangkan pada out put SPSS pada bagian Normal P-P Plot of Regresion Standardized Residual, dapat dijelaskan bahwa data-data (titiktitik) cenderung lurus mengikuti garis diagonal sehingga data dalam penelitian ini cenderung berdistribusi normal, seperti terlihat pada Gambar 2. dibawah ini.

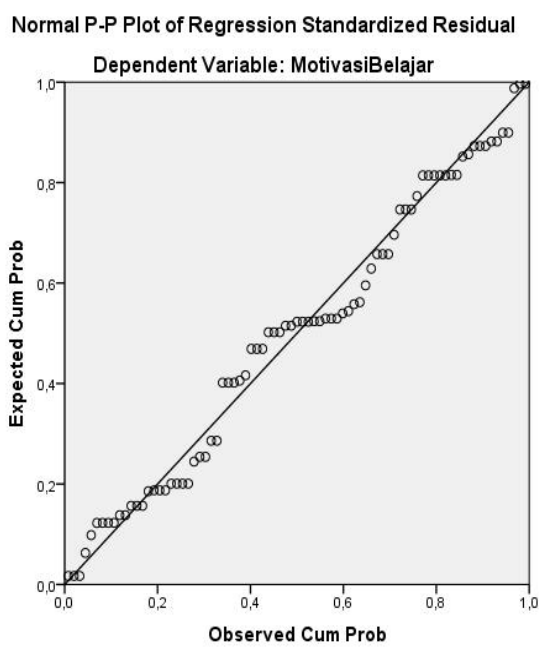

Gambar 2. Uji Normalitas 


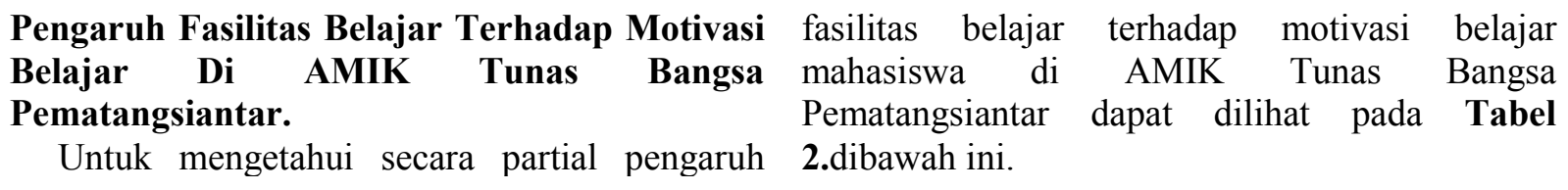

Tabel 2. Coefficients Fasilitas Belajar

\begin{tabular}{lllllll}
\hline \multirow{2}{*}{ Model } & & \multicolumn{2}{l}{$\begin{array}{l}\text { Unstandardized } \\
\text { Coefficients }\end{array}$} & $\begin{array}{l}\text { Standardized } \\
\text { Coefficients }\end{array}$ & \multirow{2}{*}{ Sig. } \\
\cline { 2 - 6 } & & $\mathrm{B}$ & Std. Error & Beta & & \\
\hline 1 & (Constant) & 14,726 & 3,692 & & 3,988 & 000 \\
\cline { 2 - 6 } & $\begin{array}{l}\text { Fasilitas } \\
\text { Belajar }\end{array}$ &, 163 &, 068 &, 246 & 2,390 &, 019 \\
\hline
\end{tabular}

a Dependent Variable: Kepuasan kerja - Hasil pengolaha data-2017

Dari Gambar 2. diatas diketahui bahwa nilai thitung $>$ ttabel $(2.390>1,991)$ maka diputuskan koefisien regresi signifikan atau H0 ditolak dan menerima hipotesis dalam penelitian ini yaitu variabel fasilitas belajar secara partial berpengaruh positif dan signifikan terhadap motivasi belajar mahasiswa di AMIK Tunas Bangsa Pematangsiantar. Hal ini dapat dibuktikan pula dari nilai Probabilitas $=0,019$, atau $\mathrm{P}<0,05$, berarti koefisien regresi fasilitas belajar secara partial signifikan pada tingkat kepercayaan $95 \%$ $(\alpha: 0,05)$.

\section{Pengaruh Lingkungan Belajar Terhadap Motivasi Belajar Di AMIK Tunas Bangsa Pematangsiantar.}

Untuk mengetahui secara partial pengaruh lingkungan belajar terhadap motivasi belajar mahasiswa Di AMIK Tunas Bangsa Pematangsiantar dapat dilihat pada Tabel 3.dibawah ini.

Tabel 3. Coefficientsa Lingkungan Belajar

\begin{tabular}{|c|c|c|c|c|c|c|}
\hline \multirow[t]{2}{*}{ Model } & & \multicolumn{2}{|c|}{$\begin{array}{l}\text { Unstandardized } \\
\text { Coefficients }\end{array}$} & \multirow{2}{*}{$\begin{array}{l}\begin{array}{l}\text { Standardized } \\
\text { Coefficients }\end{array} \\
\text { Beta }\end{array}$} & \multirow{2}{*}{$\mathrm{T}$} & \multirow[t]{2}{*}{ Sig. } \\
\hline & & $\mathrm{B}$ & Std. Error & & & \\
\hline \multirow[t]{2}{*}{1} & (Constant) & 14,726 & 3,692 & & 3,988 & ,000, \\
\hline & $\begin{array}{l}\text { LingkunganBelaj } \\
\text { ar }\end{array}$ &, 355 & ,084 & ,415 & 4,229 &, 000 \\
\hline
\end{tabular}

a. Dependent Variable: MotivasiBelajar - Hasil pengolaha data-2017

Dari Tabel 3. diatas diketahui bahwa nilai thitung $>$ ttabel $(4,229>1,991)$ maka diputuskan koefisien regresi signifikan atau $\mathrm{HO}$ ditolak dan menerima hipotesis dalam penelitian ini yaitu variabel disiplin secara partial berpengaruh positif dan signifikan terhadap kepuasan kerja dosen di AMIK Tunas Bangsa Pematangsiantar. Hal ini dapat dibuktikan pula dari nilai Probabilitas $=$
0,000 ; atau $\mathrm{P}<0,05$; berarti koefisien regresi disiplin secara partial signifikan pada tingkat kepercayaan $95 \%(\alpha: 0,05)$.

Pengaruh Fasilitas Belajar Dan Lingkungan Belajar Terhadap Motivasi Belajar Di AMIK Tunas Bangsa Pematangsiantar.

Tabel 4. Coefficientsa Fasilitas Belajar

\begin{tabular}{|c|c|c|c|c|c|c|c|}
\hline \multirow[b]{2}{*}{ Model } & \multirow[b]{2}{*}{$\mathrm{R}$} & \multirow[b]{2}{*}{$\begin{array}{l}\mathrm{R} \\
\text { Square }\end{array}$} & \multirow[b]{2}{*}{$\begin{array}{l}\text { Adjusted } \\
\text { R Square }\end{array}$} & \multicolumn{4}{|c|}{ Change Statistic } \\
\hline & & & & $\begin{array}{l}\text { Std. Error of } \\
\text { the Estimate }\end{array}$ & $\begin{array}{l}\mathrm{F} \\
\text { Change }\end{array}$ & df1 & $\mathrm{df} 2$ \\
\hline 1 &, $709^{a}$ & ,502 & ,483 & 1,28396 &, 502 & 25,872 & 3 \\
\hline
\end{tabular}

a. Predictors: (Constant), LingkunganBelajar, Fasilitas Hasil pengolaha data-2017

Dari tabel 4. di atas diketahui bahwa nilai korelasi secara simultan antara FasilitasDan 
Lingkungan Belajar Terhadap Motivasi Belajar sebesar 0,709. Nilai korelasi ini dapat dikategorikan pada korelasi yang kuat karena berada pada interval $(0,60-0,799)$.Kemudian untuk membuktikan kebenaran hipotesis penelitian atau apakah nilai korelasi itu dapat digeneralisasikan, maka harus diuji signifikansinya dengan uji-F, dan dari pengolahan data diketahui nilai Fhitung sebesar 25,872. Nilai F-hitung ini selanjutnya diinterpretasikan dengan nilai Ftabel dan dengan tingkat kpercayaan 95\% $(\alpha=0,05)$, dengan $\mathrm{dk}$ pembilang $=\mathrm{k}$ dan $\mathrm{dk}$ penyebut $=(\mathrm{n}-\mathrm{k}-1)=81-3-1=77$, maka nilai Ftabel $=2,720$. Jadi dari hasil perhitungan uji signifikan, dapat dilihat bahwa nilai Fhitung $>$ Ftabel yaitu 25,872> 2,720, jadi hipotesis penelitian secara simultan dapat dibuktikan yaitu terdapat pengaruh positif dan signifikan antara fasilitasdan lingkungan belajar terhadap motivasi belajarmahasiswa di AMIK Tunas Bangsa Pematangsiantar.

Selanjutnya untuk mengetahui seberapa besar pengaruhfasilitas, dan lingkungan belajar terhadap motivasi belajar di AMIK Tunas Bangsa Pematangsiantar, maka diuji dengan uji determinan (D). Dari pengolahan data diperoleh nilai $r^{2}$ (Rsquare) sebesar 0,502, maka dapat diketahui nilai Determinannya adalah $0,502 \mathrm{x}$ $100 \%=50,20 \%$, yang berarti bahwa variabel persepsi fasilitasdan lingkungan belajar secara simultan berpengaruh terhadap motivasi belajar sebesar 50,20\%, dan sisanya sebesar $49,80 \%$ dipengaruhi oleh faktor-faktor lain yang tidak diteliti.

\section{Analisis Regresi Linier Berganda}

Analisis regresi linier berganda ini digunakan untuk mengestimasi pengaruhpersepsi mahasiswa mengenai kompetensi dosen, fasilitas,dan lingkungan belajar terhadap motivasi belajar di AMIK Tunas Bangsa Pematangsiantar. Berdasarkan hasil pengolahan data diperoleh hasil sebagai berikut :.

\section{Coefficients $^{\mathrm{a}}$}

Tabel 5. Hasil Uji Signifikansi Variabel Independent

\begin{tabular}{lllllll}
\hline \multirow{2}{*}{ Model } & \multicolumn{2}{l}{$\begin{array}{l}\text { Unstandardized } \\
\text { Coefficients }\end{array}$} & \multicolumn{2}{l}{$\begin{array}{l}\text { Standardized } \\
\text { Coefficients }\end{array}$} & \multirow{2}{*}{ Sig. } \\
\cline { 2 - 5 } & $\mathrm{B}$ & Std. Error & Beta & & \\
\hline 1 & (Constant) & 14,726 & 3,692 & & 3,988 &, 000 \\
& Fasilitas &, 163 &, 068 &, 246 & 2,390 &, 019 \\
& LingkunganBelajar &, 355 &, 084 &, 415 & 4,229 &, 000 \\
\hline
\end{tabular}

a. Dependent Variable: MotivasiBelajar - Hasil pengolaha data-2017

Berdasarkan pada Tabel 5. diatas, persamaan regresi linier berganda adalah sebagai berikut :

$$
Y=14,726+0,163 \times 1+0,355 X 2+\varepsilon
$$

Dengan persamaan regresi linier berganda tersebut dapat dijelaskan bahwa:

a. Nilai konstanta adalah sebesar 14,726 , hal ini menyatakan bahwa jika fasilitas dan lingkungan belajar diabaikan maka nilai motivasi belajar mahasiswa sebesar 14,726 .

b. Koefisien regresi untuk variabel fasilitas sebesar 0,163, hal menunjukkan bahwa setiap kenaikkan $1 \%$ faktor fasilitas maka motivasi belajar mahasiswa akan meningkat sebesar $1,63 \%$.

d. Koefisien regresi untuk variabel lingkungan belajar sebesar 0,355, hal menunjukkan bahwa setiap kenaikkan $1 \%$ faktor lingkungan belajar maka motivasi belajar mahasiswa akan meningkat sebesar 3,55\%.

\section{KESIMPULAN DAN SARAN}

\section{Kesimpulan}

1. Fasilitasbelajar secara partial berpengaruh positif dan signifikan terhadap motivasi belajar mahasiswa di AMIK Tunas Bangsa Pematangsiantar dapat dilihat dari nilai thitung $>$ ttabel $(2,390>1,991)$.

2. Lingkungan belajar secara partial berpengaruh positif dan signifikan terhadap motivasi belajar mahasiswadi AMIK Tunas Bangsa Pematangsiantar dapat dilihat dari nilai thitung $>$ ttabel $(4,229>1,991)$.

3. Persepsi mahasiswa mengenai kompetensi dosen, fasilitas,dan lingkungan belajar secara simultan berpengaruh positif dan 
signifikan terhadap motivasi belajar mahasiswa di AMIK Tunas Bangsa Pematangsiantar, dapat dilihat dari nilai Fhitung $>$ Ftabel yaitu $(25,872>2,720)$, dan secara prosentase pengaruh variable $\mathrm{X} 1$, X2,dan X3 terhadap Yr sebesar 50,20\%, dan sisanya sebesar 49,80\%dipengaruhi oleh faktor-faktor lain yang tidak diteliti.

\section{Saran}

Berdasarkan hasil penelitian, maka penulis bermaksud memberikan saran atau masukan yang mungkin bermanfaat bagi AMIK Tunas Bangsa Pematangsiantar antara lain :

1. Fasilitas yang telah dijanjikan kepada calon mahasiiswa dahulu sewaktu mendaftar seperti ruangan yang nyaman, area parkir yang luas dan aman, wifi gratis 24 jam, dosen yang profesional dan kompeten di bidangnya agar direalisasikan setelah mereka menjadi mahasiswa.

2. Menciptakan lingkungan yang sehat dan kondusif kepada seluruh elemen kampus, baik lingkungan belajar maupun lingkungan pergaulan.

3. Kepada peneliti selanjutnya kiranya dapat menambah variabel lain jika ingin melakukan penelitian yang sejenis.

\section{DAFTAR PUSTAKA}

Arikunto, Suharsimi. (2006). Manajemen Penelitian. Jakarta: Rineka Cipta. Azwar, S. (2000). Reliabilitas dan Validitas. Yogyakarta: Pustaka Pelajar Offset.

Arikunto, Suharsimi. 2002. Prosedur Penelitian suatu Pendekatan Praktek. Jakarta: Rineka Cipta.

Baihaqi dkk, 2005.Psikiatri ( Konsep Dasar dan Gangguan-gangguan ). Bandung : Refika Aditama.

Dariyo, Agus. (2008). Psikologi Perkembangan Dewasa Muda. Jakarta: PT Grasindo. Departemen Pendidikan Nasional.(2009). Sistem Pendidikan.

Darsono, Max dkk. 2000. Belajar Dan Pembelajaran. Semarang: IKIP

Depdiknas. 2005. Undang-Undang No.14 Tahun 2005.Guru dan Dosen.Bandung. Fokusmedia.

Djamarah, Syaiful Bahri. (2002) Psikologi Belajar. Jakarta: Rineka Cipta.

Ghozali, Imam. 2001. Aplikasi Analisis multivariate dengan program SPSS. Semarang: Badan Penerbit Universitas Diponegoro
Gunawan, Ary H., 2000, Sosiologi Pendidikan: Suatu Analisis Sosiologi tentang Pelbagai Problem Pendidikan, Jakarta: Rineka Cipta.

Hadikusumo, Kunaryo, dkk. 1996. Pengantar Pendidikan. Semarang: IKIP Semarang Press.

Hakim, Thursan, 2000, Belajar Secara Efektif, Jakarta: Pupsa Swara.

Hamid, Sanusi. 2015. Manajemen Sumber Daya Lamjutan. Yogyakarta: Deepublish.

Handayani, Santhy. 2005. Hubungan tentang Kinerja Guru PPL Dengan Motivasi Belajar Siswa Tingkat I SMK Negeri 5 Bandung. Skripsi FPTK UPI Bandung. Tidak Diterbitkan.

Sanadi, Lukman. 2013.Pengaruh Motivasi dan Pemanfaatan Fasilitas Belajar Terhadap Prestasi Belajar. Jurnal Pendidikan Ekonomi (JUPE)Vol 1 No.3 E-Journal UNESA

Sardiman AM. 2001. Interaksi dan Motivasi Belajar Mengajar. Jakarta: Raja Grafindo Persada.

Slameto.2003. Belajar Dan Faktor-Faktor Yang Mempengaruhinya. Jakarta: Rineka Cipta.

Sugiyono. 2005. Statistika Untuk Penelitian. Bandung: Alfabeta

Sugiyono. 2012.Metode Penelitian Pendidikan, Bandung: Alfabeta

Sumiati. 2012 Pengaruh Lingkungan Belajar Siswa TerhadapMotivasi Belajar dan Implikasinyat terhadapHasil Belajar Siswa Pada Mata Pelajaran Ekonomi Syariah Di Smp Kota Tasikmalaya.Jurnal Pendidikan Ekonomi dan Koperasi, Vol. 7, No. 1.

Tirtarahardja, La Sulo, 1994, Pengantar Pendidikan Edisi Revisi, Yogyakarta, Rineka Cipta.

Wuryani, Sri Esti. 2002. Psikologi Pendidikan. Jakarta: PT Grasindo. 